\title{
Acceptance of Smartphone in Enhancing Patient-Caregivers Relationship
}

\author{
Wan Khairuzzaman Wan Ismail', Paul Chan Hong Kit², Nora Buhari ${ }^{3}$,Azlina Muzaini ${ }^{4}$
}

\begin{abstract}
Patients may take more initiative to give more attention to their health as well as foster closer relationship with the caregivers and this has been made possible through smartphone. This paper investigates the perceived usefulness of smartphone among healthcare personnel in a private hospital setting. The study has identified elements which have had impact on individual decision to use smartphones using Technology Acceptance Model (TAM). Questionnaires were distributed to 57 respondents including medical doctors, nurses and head of department of a hospital. The analysis shows that the younger generations were more 'trendy' in owning a Smartphone. The study indicates that females reported better acceptance of smartphone use in their works. Healthcare industry will be more patient-centric instead of doctorcentric, hence, it is important for healthcare providers to provide services in line with the customers' requirement without jeopardizing patient safety and lives.
\end{abstract}

Keywords: healthcare provider; patient-caregiver relation; smartphones; mobile communication technology.

\footnotetext{
' International Business School, Universiti Teknologi Malaysia, Jalan Semarak, 50400, Kuala Lumpur, Malaysia, 6019-4616464, E-mail: mwkhair@ibs.utm.my

2 Ministry of Health, Putrajaya, Malaysia, Blok EI, E6, E7 \& EI 0, Parcel E, Pusat Pentadbiran Kerajaan Persekutuan, 62590 Putrajaya,Wilayah Persekutuan, 603-26948969, E-mail: drpaul.chk@moh.gov.my

${ }^{3}$ KPJ Healthcare Berhad, 202-A, Jalan Pahang, 53000, Kuala Lumpur, Malaysia 603-40226222, E-mail: nora.mba.utm@gmail.com

${ }^{4}$ KPJ Healthcare Berhad,Kuala Lumpur, Malaysia, 603-40226222, E-mail: azlina@dsh.kpjhealth.com.my
}

ISSN: 07 I8-2724. (http://www.jotmi.org)

Journal of Technology Management \& Innovation (c) Universidad Alberto Hurtado, Facultad de Economía y Negocios. 


\section{Introduction}

The ageing population, global climate warming, changes in the environment are some of the emerging challenges that affect our health and healthcare (Alasaarela et al., 2009, Maqueira and Bruque, 2007). Based on Kalorama's market study, the development wireless technologies is a result of the rising demand to improve the healthcare processes via technical product and services. Wireless technologies increase the ability of healthcare providers to improve patient care, reduce cost, streamline processes, and comply with government rules and regulation by providing access to realtime data at the point-of-care (Kalorama, 2009).

In short, mobile communications technology assists the healthcare providers by enabling physicians and nurses to expedite access to high-risk patients' information anytime, anywhere, thus saving their lives. Therefore, the patients may give more attention to their health as well as foster closer relationship with the caregivers (Chao et al., 2007). This could be done via smartphone. A 2009 survey Manhattan Research on usage of smartphone by the physicians found that $64 \%$ of US physicians owned a smartphone (Dolan, 2009). The study further predicted that by 2012 the proportion of smartphone owners would increase to $81 \%$. Research also suggests that within the next few years, more people will be accessing the internet via mobile devices than through traditional desktop computers (Stanley, 2009; Kelly, 2010) hence the need for healthcare organizations to prepare their employees for the changes in technology.

The purpose of this paper is to investigate the perceived usefulness of smartphone among healthcare personnel i.e. the medical consultants, nursing personnel and other key personnel in a private hospital setting in Malaysia. The authors believe that since the case hospital has started implementing the Clinical Information System (CIS), smartphone usage among the respondents could enhance and complement the CIS without jeopardizing the quality services rendered to the patients. Thus, the study identifies elements that have had impact on decision taken by individuals to use smartphones using Technology Acceptance Model (TAM). For the purpose of the study, the words smartphones and mobile computing is used interchangeably.

Next section consists of literature review on the use of smartphone and perceived usefulness followed by a discussion on Technology Acceptance Model. Subsequently, the authors present research methodology followed by analysis and discussion of the results. The final past discusses implication to research and practice and conclusions of the study.

\section{Literature review}

Smartphone is a phone with advanced feature such as Windows Mobile, internet access as well as other computer processing capabilities (Putzer and Park, 2010). It comes with enhanced functionality more than merely making and receiving call and send text messages. It can check and send email, play video, display photos, surfing the internet. Smartphone such as iPhone and android-based phone offers unlimited functionality due to its ability to run third party application (TechTerms.com, 20I2). A combination of a personal digital assistant (PDA) and a cell phone, a smartphone is able to run a computer program and run operating system (OS), allows download of software applications to be run on the phone (Michael, 20II) such as Apple's iPhone with more than 350,000 applications is able to perform variety of function (n.a., 20l I).

The rapid development in ICT opens opportunities as well as challenges to offer efficient and high quality healthcare services, eliminate medical errors, streamline the care-givers' workflow, provide decision support at the point of care, lower the cost and enhance the doctor-patient relationship (Wu et al., 2009). Example is via implementation of clinical information system (CIS) which has always been associated with efficient mechanism to provide quality care via effective information retrieval as well as efficient data management (Palm et al., 2006). Despite the fact that there has been increasing support on usage of electronic medical record, technology has started to adopt (Bower, 2005).

According to a survey carried out in 1999, out of 769 doctors, 15 percent of them use Personal Digital Assistant (PDA). The study also indicated that utilization of PDA rate in $200 \mathrm{I}$ which has increased by 18 percent among the doctors has shown significant improvement in year 2004 and 2005 whereby utilization rate ranged between 57 percent and 91 percent depending on the medical discipline (Silva et al., 2003).

There are many benefits of using smartphones in the healthcare industry which were quoted by various researchers. Smartphone provides a mechanism for both doctors and nurses to access the internet to carry out research as well as serve its basic function for communication purposes (Kirschner and Powell, 2005). In addition, studies by Silva et al., 2003 shows that usage of PDA by the pharmacists and doctors to deliver clinical services has resulted in cost saving of USD662,000 during six months period, indicating a significant cost saving to provide healthcare services. Another study by Leung et al. (2003), found that usage of handheld communication gadget managed to improve the evidencebased medicine and enhance education services among the clinicians while other study in an aged care facility in Aus-

ISSN: 07I 8-2724. (http://www.jotmi.org)

Journal of Technology Management \& Innovation (C) Universidad Alberto Hurtado, Facultad de Economía y Negocios. 
tralia found that usage of handheld communication device offers two-way 'live' transfer of clinical information at the point of care (Chau and Turner, 2006).

\section{Use of Smartphone by Caregivers}

According to Sarasohn-Kahn, 2010, up to February 2010, there were I,567 applications in the Apple Store for iPhone specifically intended for the healthcare professionals which offers the clinicians variety of information that they can access from the smartphone. The applications allows clinicians to access the patients' electronic medical record, information on medication, result of laboratory test, clinical decision support tools, etc. (Hamou et al., 20l0).

Epocrates which offer free drug references for iPhone, android, Palm OS, Windows Mobile and Blackberry is a wellknown medical references applications that allows physicians to have access to the information pertaining to the right dosage of drugs, drug interaction as well as adverse reaction. Subsequently, physicians could prescribe drugs that require no tamperproof paper right from the smartphone since the software allows them to check the drug information, and calculate the right dose. For example, Differential Diagnosis i-Pocket gives the doctors information on 800 signs and symptoms as well as abnormal findings from various conditions which could facilitate diagnosis process (Michael, 20II). Availability of special features in the iPhone such as motion sensors and accelerometers can be used as a mechanism to measure a person's movement, agility and activity level and might help the care provider to diagnose mental health disorder to due to deteriorating activity level. On top of the implementation of the electronic health record (HER), hospital information system (HIS) and clinical information system (CIS), the advent of mobile health (mHealth) technology indicated that there are vast opportunities on usage of the smartphone to explore the possibility of implementing mobile health (mHealth) program. mHealth enables early intervention, motivate the patients, improve trust to the care providers as well as remote patient monitoring (Coye et al., 2009) whenever and wherever. Several studies have stated that in order to ensure efficiency in delivering healthcare services, healthcare professionals need to have access to the patient and medical information anytime, anywhere, while carrying out daily ward rounds (Haux, 2006; Johnson and Turley, 2006). Mobile computing such as via smartphone enables the care providers to provide clinical input pertaining to patient care in effective and efficient manner at the point of care with the intention of minimizing medical errors. However, the actual result is far from desired.

\section{Relevance of Technology Acceptance Model (TAM)}

Basically, Technology Acceptance Model (TAM) was formulated as a mechanism to explain and predict consumer's acceptance of information technology and information system (IT/IS) (Davis, 1989). Originally, there are five elements of TAM: perceived usefulness (PU), perceived ease of use (PEOU), attitude toward using, behavioural intention (BI) to use, and actual system use (Wu and Chang, 2005).According to TAM, decision on adoption a system is determined by two main factors: Perceived Usefulness (PU) and Perceived Ease of Use (PEOU) as depicted in Figure I below.

Perceived usefulness (PU) is the extent a person feels that utilization of a specific technology would improve his or her job performance, while perceived ease of use (PEOU) is referring to the degree a person feels that utilization of a particular technology requires no effort (Davis, 1989). Based on a study carried out by Kang et al., 20 I I, four main functional features i.e. wireless internet connection, multimedia, system/application and after-sale service have had a significant effect on PU and PEOU while design only affect PU which means that the convenience can be improved by having superior design although it has nothing to do with usefulness. The study which found that PU significantly affects the behavioral intention (BI) directly is useful to analyze the mar-

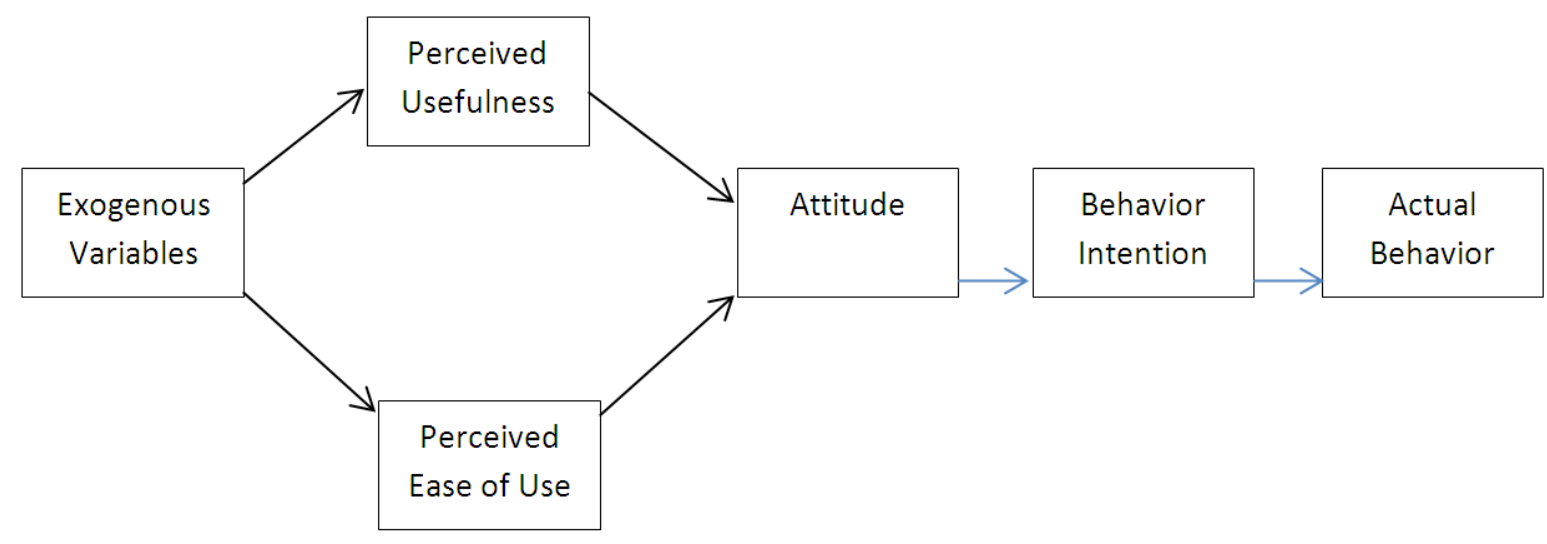

Figure I. Basic Concept of TAM. Source: Davis, 1989; Kang et al., 201 I.

ISSN: 07I 8-2724. (http://www.jotmi.org)

Journal of Technology Management \& Innovation (C) Universidad Alberto Hurtado, Facultad de Economía y Negocios. 
ket for the smartphone and the consumers, which ultimately could support design for the new product development as well as the marketing strategies.

A study by Chua and $\mathrm{Hu}, 200 \mathrm{I}$ concluded that TAM is more relevant to determine the acceptance of the clinical professionals on the tele-medicine technology. It was also found that PU and PEOU have had an influence on the user's intention to carry out their job (Fang et al., 2005). In the internet environment, PU, PEOU, system complexity as well as influence from socio aspects has had an impact on the acceptance of wireless internet through mobile technologies (Lu et al., 2005). A study in Finland on utilization of mobile communication system among doctors found that PU played significant role in the doctors' intention to use mobile system (Han et al., 2006). Since healthcare information is associated with safety and security of data, it is worth mentioning a study by Gupta and Xu (2010) which concluded that safety awareness and security concerns significantly influence the acceptance of a risky technology.

Under TAM, PU is seen from the perspective of how a system is able to enhance the performance of the users (Davis, 1989) whereas in general, since smartphone is closely related to the availability of mobile service anytime, anywhere, $\mathrm{PU}$ is referring to the extent the mobile communication service is able to be integrated into a person daily activities (Kleijen et al., 2004). Yangil and Chen (2007) recommended the following model to study the acceptance on innovative use of smartphone.

TAM is described from the right half of the diagram whereby as the PU increases, the attitude of the users on usage of the smartphone will increase thus influencing the intention to utilize the smartphone. PEOU is described as the ease to navigate the gadget as well as presence of personalized features. PEOU which influence positively on the attitude towards usage of smartphone is believed to have positive impact on the PU. In short, if the users perceive the ease of use negatively, it would be very difficult for them to assess the PU of the smartphone. The model concluded that the attitude of the users on the smartphone will influence the intention to use the smartphone positively (Yangil and Chen, 2007).

\section{Methodology}

The case hospital is a private hospital located in the heart of Kuala Lumpur, Malaysia. Accommodating 168 beds, the hospital is categorised under medium in size and known as one of the largest and reputable hospitals and is chosen for this because of its scale, various medical specialties and high throughput of patients. There were 25 doctors, 25 nurses and 25 non-clinical key personnel invited to participate in the study. Selection of the reespondents was based on convenience sampling. Questionnaires were distributed to respondents with the cooperation of the hospitals' Human Resource Manager.

The questionnaires was adopted from Yangil and Chen, 2007. It was divided into 12 variables: Self Efficacy (SE), Perceived Usefulness (PE), Behavioural Intention, Triability, Observability, Compatibility, Task, Individual, Organisation and Environment. Variable Likert scale of I indicates 'Strongly Disagree', 2 'Disagree', 3 'Neutral', 4 'Agree' and 5 'Strongly Agree' had been used. Cronbach's coefficient $\nabla$ were conducted to es-

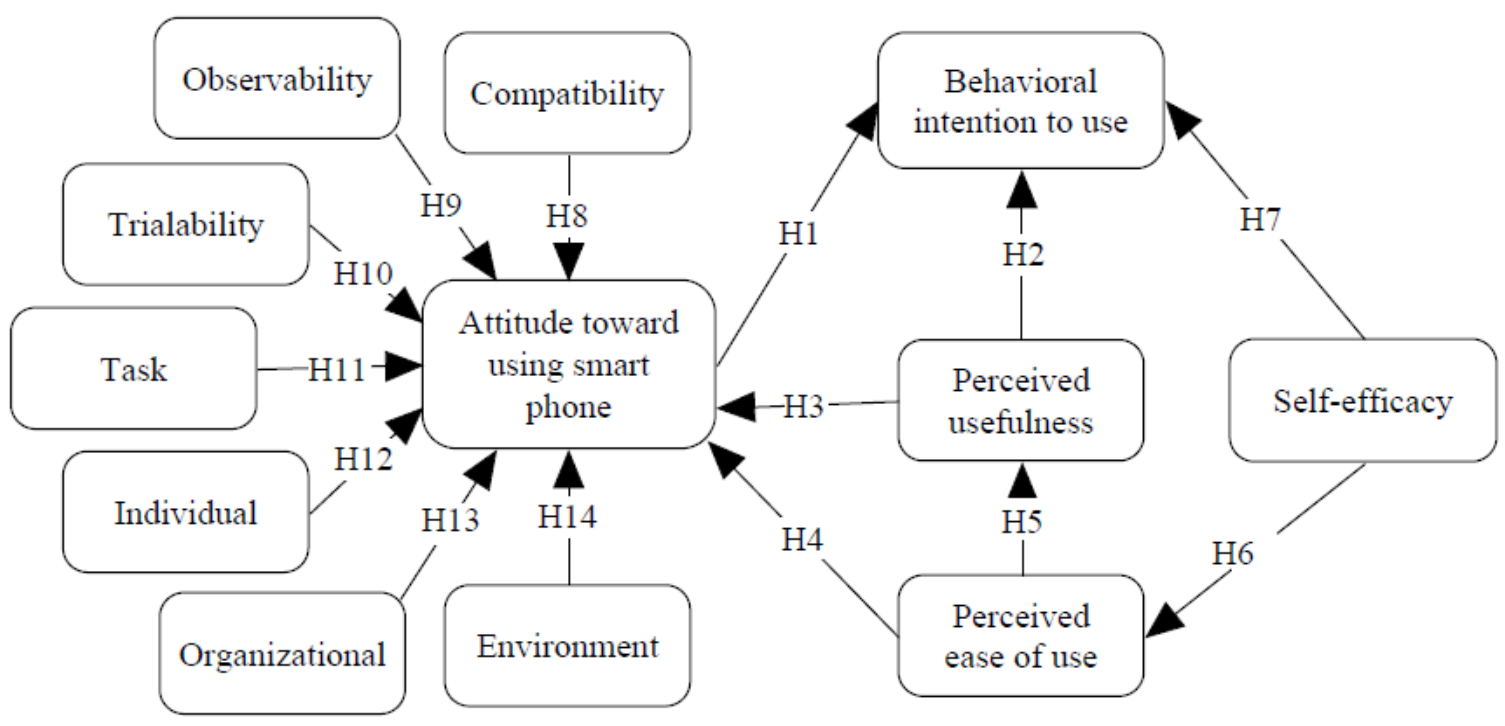

Figure 2. Model to access acceptance of smartphone via TAM. Source: Yangil and Chen, 2007.

ISSN: 07I 8-2724. (http://www.jotmi.org)

Journal of Technology Management \& Innovation (C) Universidad Alberto Hurtado, Facultad de Economía y Negocios. 
timate internal reliability of multi-items and to re-establish the validity and the reliability of the questionnaires. Two weeks after the distribution of the questionnaires, a follow up was done to encourage respondents to return the survey. Any identified respondent who misplaced the survey questionnaires will obtain a replacement from the Human Resource Manager. Approximately four weeks were allocated for distribution and collection of the questionnaires.

\section{Analysis}

The researchers developed an arbitrary score for each of the response in the Likert scale of the questionnaire. A score of I indicates 'Strongly Disagree', 2 'Disagree', 3 'Neutral', 4 'Agree' and 5 'Strongly Agree' and an arbitrary score for each of the response in the Likert scale of the questionnaire has been developed to identify the 'acceptable' score by calculating median between lowest and highest acceptance score.
A total of 75 questionnaires were distributed throughout the study period. These questionnaires were divided equally among Doctors, Head of Services and Nursing staffs. The Head of Services provided the highest response at 23 out of 25 while the lowest was the consultants/doctors, of which only 13 out of 25 of them participated in the survey (Table I).

Female dominates the study population (Table 2) where the sample consists of 42 female and 15 males. Of the 57 respondents, 23 are head of services while 21 are nurses. Of the participants, 22 indicated total working experience of more than 10 years, 23 has got experience between I to 10 years while only 12 has total working experience of less than I year. Almost half of the respondents are at the age group between $3 \mathrm{I}$ to 46 years old, $2 \mathrm{I}$ at the age 30 years and below and the rest is more than 46 years old. The highest number of respondents seems to be in the Generation $X$ and $Y$ group. More than two-third of the respondents indicate the use of smart-phones.

\begin{tabular}{lcccc}
\hline \multicolumn{1}{c}{ Questionnaires } & Doctors & Nurses & Head of Services & Total \\
\hline Distributed & 25 & 25 & 25 & 75 \\
Returned & 13 & 21 & 23 & 57 \\
Percentage & $52 \%$ & $84 \%$ & $92 \%$ & $76 \%$ \\
\hline
\end{tabular}

Table I. No of questionnaires distributed and returned.

\begin{tabular}{llr}
\hline Profile & & Frequency \\
\hline Gender & Male & 15 \\
& Female & 42 \\
& Total & 57 \\
\hline Position & Medical doctors & 13 \\
& Nurses & 21 \\
& Head of services & 23 \\
\hline Work experience & $<1$ yr & 12 \\
& $1-<10$ yrs & 23 \\
& $>10$ yrs & 22 \\
& Total & 57 \\
\hline Age Group & $<30$ yrs. & 21 \\
& between $31-46$ & 28 \\
& $>46$ & 8 \\
& Total & 57 \\
\hline Use of Smartphone & Yes & 43 \\
& No & 14 \\
& Total & 57 \\
\hline
\end{tabular}

Table 2. Profile of Respondents.

ISSN: 07I 8-2724. (http://www.jotmi.org) 


\begin{tabular}{|cccc|}
\hline Variable & Mean & SD & Cronbach's cofficient $\alpha$ \\
\hline SE & 3.49 & 0.98 & 0.905 \\
PU & 3.63 & 0.98 & 0.951 \\
PEAU & 3.62 & 0.87 & 0.934 \\
BI & 3.82 & 0.84 & 0.840 \\
AT & 3.44 & 1.00 & 0.597 \\
TI & 3.7 & 0.89 & 0.798 \\
OB & 3.45 & 0.98 & 0.930 \\
CM & 2.29 & 0.922 & 0.898 \\
TASK & 3.28 & 0.98 & 0.877 \\
IND & 3.48 & 0.91 & 0.848 \\
ORG & 3.67 & 0.93 & 0.911 \\
ENV & 3.61 & 0.89 & 0.747 \\
\hline
\end{tabular}

Table 3.Internal Reliability of Multi-items.

Cronbach's coefficient $\nabla$ is used to estimate internal reliability of multi-items. The coefficient rate of more than 0.70 is generally considered to be acceptable. Table 3 shows the coefficient $\otimes$ for each of the variables.All of them are acceptable except for AT which has the coefficient of 0.567 . Overall Cronbach's $\otimes$ is 0.972 indicating a high internal reliability.

The authors developed an arbitrary score for each of the response in the Likert scale of the questionnaire. A score of I indicates 'Strongly Disagree', 2 'Disagree', 3 'Neutral', 4 'Agree' and 5 'Strongly Agree'. The lowest score attainable is 57 , i.e if all the respondents score ' $I$ ' while the highest score will be 285. A median between these two extremes, 17I, was taken as the 'acceptable' score. A score that is higher than I7I will indicate that Smartphone has got good acceptance in its use at work while a score that is less 171 indicates that Smartphone has got poor acceptance. Figure 3 a graphical representation of all respondents which indicates that majority of the respondents score higher than 171 as indicated by a horizontal red line.

Contrary to popular belief that female has higher acceptability on the use of Smartphone at work and this difference is significant $(p=0.01)$. Regardless of the work experience, more participants has perceived Smartphones to be useful at work $(p=0.01)$, as shown in Table 4 and 5.

More participants from the Generation $X$ and $Y$ has got higher acceptability on the use of Smartphone compared with those from the baby boomers ( $>46$ years) (Table 6 ).

The analysis also shows that there are also no significant difference among doctors, head of services and nurses on the use of Smartphones (Table 7).

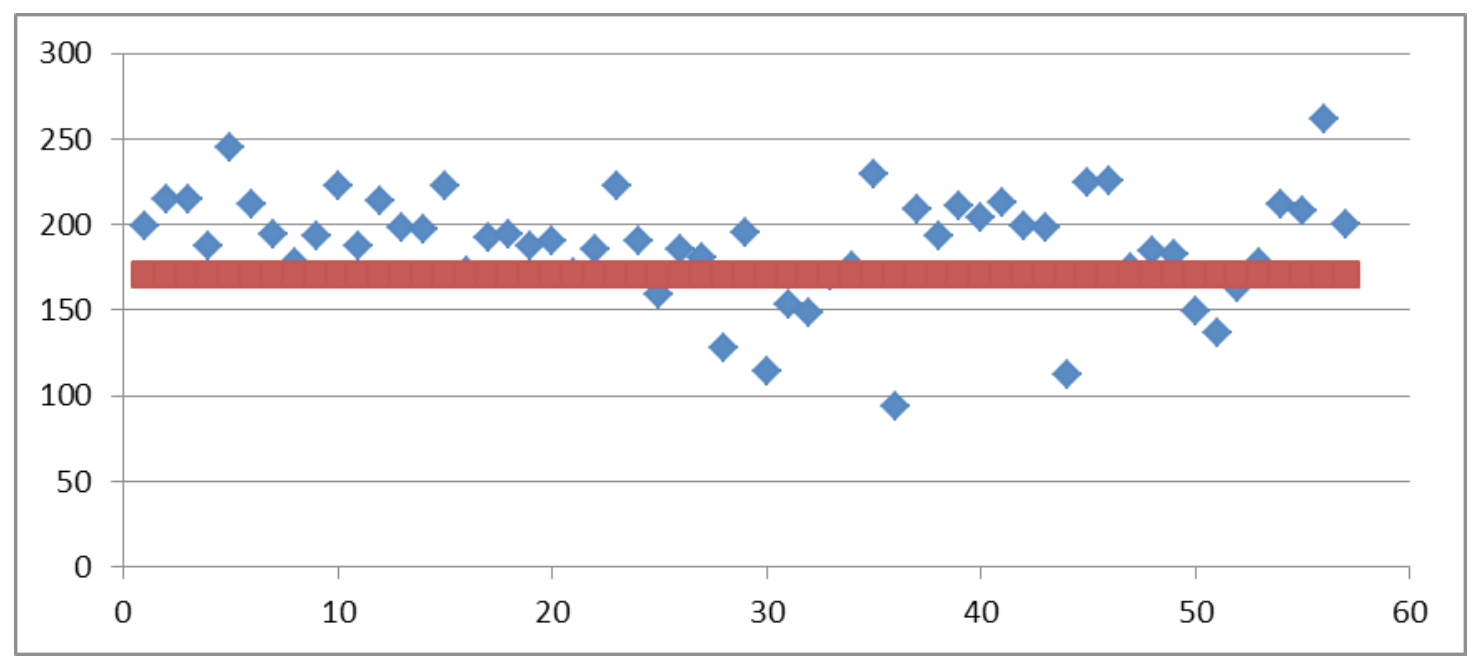

Figure 3. Scatterplot Diagram.

ISSN: 07 I8-2724. (http://www.jotmi.org)

Journal of Technology Management \& Innovation (C) Universidad Alberto Hurtado, Facultad de Economía y Negocios. 


\begin{tabular}{|l|l|c|c|c|}
\hline & & \multicolumn{2}{|c|}{ Useful } & \\
\hline & & Yes & No & Total \\
\hline Gender & Male & 13 & 2 & 15 \\
\hline & Female & 34 & 8 & 28 \\
\hline
\end{tabular}

Table 4. Perceived Usefulness by Gender.

\begin{tabular}{|l|l|c|c|c|}
\hline & & \multicolumn{2}{|c|}{ Useful } & Total \\
\hline & & Yes & No & 12 \\
\hline Years of experience & $<1$ year & 10 & 2 & 23 \\
\hline & $1-10$ & 19 & 4 & 12 \\
\hline & $>10$ & 8 & 4 & \\
\hline
\end{tabular}

Table 5. Perceived Usefulness by Experience.

\begin{tabular}{|l|l|c|c|c|}
\hline & & \multicolumn{2}{|c|}{ Useful } & \\
\hline & & Yes & No & Total \\
\hline Age group & $<30 \mathrm{yrs}$ & 17 & 4 & 21 \\
\hline & $31-46 \mathrm{yrs}$ & 23 & 5 & 28 \\
\hline & $>46$ & 7 & 1 & 8 \\
\hline
\end{tabular}

Table 6. Perceived Usefulness by Age Group.

\begin{tabular}{|l|l|c|c|c|}
\hline & & \multicolumn{2}{|c|}{ Useful } & \\
\hline & & Yes & No & Total \\
\hline Job Title & Medical doctors & 7 & 6 & 13 \\
\hline & Nurses & 17 & 4 & 21 \\
\hline & Head of services & 23 & 0 & 23 \\
\hline
\end{tabular}

Table 7. Perceived Usefulness by Job Title.

\section{Conclusions}

The use of smartphones in Malaysia is no stranger to many of us. More and more service providers are making its use very cheap and value for the customers' money. The results from this empirical study indicate that the acceptance level is high among healthcare providers on the use of smartphones in health services. The findings also show that the younger generation i.e Generation Y (born after 1982) and Generation $X$ (born between 1961 and 198I) in the case hospital has the tendency to be more 'trendy' in wanting to own a Smartphone. Hence, this makes the use of smartphones among these two groups significantly higher as shown in this study.
Contrary to popular belief that males are 'better' users of electronic gadgets, the study indicates significantly higher of females perceived better acceptance of smartphone use in their works. The study results also show that there is good acceptance of the use of Smartphones among the participants of the study at work. This better acceptance will translate to good use of it and therefore enhance quality as well as productivity of their work. The study also found that regardless of profession, Smartphone is perceived to be useful at work. General belief is that high income profession uses more smartphones compare with the low income group. This was not the case in this study.

From the technology management perspective, one of the factors that an organisations need to consider seriously is to manage well the current and the emerging technologies to

ISSN: 07 I8-2724. (http://www.jotmi.org) 
stay competitive. This is true in healthcare industry whereby innovation is said to have been very slow particularly in the basic process, finance as well as the customer service (Coye et al., 2009). Therefore, the case hospital can use results of this survey to help develop programs to increase awareness especially among the medical consultants as well as to enhance service delivery. Subsequently, the above initiative can be strategized in tandem with the phone-doctor programme which will be implemented by its corporate headquarters in collaboration with telecommunication providers in the country. While constant efforts are taken to ensure the case hospital keeps pace with the latest technology to deliver quality healthcare services to its customer, it is also important to note that the emerging technology in the healthcare industry will be more patient-centric instead of doctor-centric. In other words, to be strategically competitive, it is of paramount importance to provide services in line with the customers' requirement without jeopardizing patient safety and lives.

\section{References}

ALASAARELA, E., Nemana, R. and Demello, S. (2009). Drivers and challenges of wireless solutions in future healthcare. Computer Information Science, 19-24.

BOWER, A. G. (2005). The diffussion of value of healthcare Information Technology. Santa Monica, CA: Rand Corporation.

CHAO, C. C., Jen, W. Y., Hung, M. C., L, Y. C. and Chi, Y. P. (2007).An innovative mobile approach for patient safety services: The case of a Taiwan health care provider. Technovation, 27, 342-35I.

CHAU, S. and Turner, P. (2006). Utilisation of mobile handheld devices for care management at an Australian aged care facility. Electronic Communication Research and Application, 5, 305-3I 2 .

CHUA, P. and Hu, P. J. (200I). Information technology acceptance by individual professionals: a model comparison approach. Decision Science, 32, 699-720.

COYE, M. J., Haselkorn, A. and Demello, S. (2009). Remote patient management: Technology-enabled innovation and evolving business models for chronic disease care. Health Affairs, 28, 126.

DAVIS, F. D. (1989). Perceived usefulness, perceived ease of use, and user acceptance of Information Technology. MIS Quarterly, 13, 319-339.
DOLAN, B. (2009). Mobi health news: Twice as many physicians use iPhones in 2009 [Online]. 20I I Chester Street Publishing, Inc.. Available at: http://mobihealthnews.com/l4I I/ twice-as-many-physicians-use-iphones-in-2009/. Date accessed: 12 Nov. 201 I.

FANG, X., Chan, S., Brzeinski, J. and Xu, S. (2005). Moderating effects of task type on wireless technology acceptance. Journal of Management Information System 22, 125-57.

GUPTA, S. and Xu, H. (2010). Examining the relative influence of risk and control on intention to adopt risky technologies. Journal of Technology Management and Innovation. Available at: http://www.jotmi.org/index.php/GT/rt/captureCite/art 172/596. Date accessed: 13 Sep. 2012.

HAMOU, A., Guy, S., Lewden, B., Bilyea, A., Gwadry-Sridhar, F. and M. Bauer, M. 20I0. Data collection with iPhone Web apps efficiently collecting patient data using mobile devices. 12th IEEE International. e-Health Networking Applications and Services (Healthcom).

HAN, S., Mustonen, P., Seppanen, M. and Kallio, M. (2006). Physicians' acceptance of mobile communication technology: an exploratory study. International Journal of Mobile Communication 4, 48-69.

HAUX, R. (2006). Health Information System - past, present, future. International Journal of Medical Informatics, 268-28I.

JOHNSON, C. M. and Turley, J. P. (2006). The significance of cognitive modelling in building healthcare interfaces. International Journal of Medical Informatics, 75, 163-172.

KALORAMA (2009). Wireless Opportunities in Healthcare. Kalorama Information.

KANG, Y. M., Cho, C. and Lee, S. (20II). Analysis of factors affecting the adoption of smartphones. IEEE Int'l Technology Management Conference. National Research Foundation of Korea (NRF).

KELLY, M. (2010). Smartphones: the new frontier for physicians. Pharmaforum [Online]. Available at: http://www.pharmaphorum.com/2010/10/12/smartphones-the-new-frontierfor-physicians/. Date Accessed: 7 Oct. $201 \mathrm{I}$.

KIRSCHNER, S. K. and Powell, N. (2005). Smartphones. Popular Science, 266, 77-86.

KLEIJEN, M., Wetzels, M. and Ruyter, K. 2004. Consumer acceptance of wireless finance. Journal of Financial Services Marketing, 8, 206-II. 
LEUNG, G. M., Johnston, J. M., Tin, K. Y., Wong, I. O., Ho, L. M., Lam,W.W. and Lam, T. H. (2003). Randomised controlled trial of clinical decision support tools to improve learning of evidence based medicine in medical students. British Medical Journal, 327, 1090.

LU,Y., Lee, J. K., Sears, A. and Jacko, J.A. (2005). A review and framework of handheld computer adoption in healthcare. International Journal of Medical Informatics, 74.

MACQUEIRA MARíN, J. and Bruque Cámara, S. (2007). Grid information technology as a new technological tool for escience, healthcare and life science. Journal of Technology Management and Innovation. Available at: http://www.jotmi. org/index.php/GT/rt/captureCite/art48/405. Date accessed: 13 Sep. 2012.

MICHAEL, S. (20I I). Application of smartphone technology in the management and treatment of mental illnesses. Master of Public Health, University of Pittsburg.

N.A. (20I I).Apple's app store downloads top 10 billion. Apple Press Info [Online]. Available at: http://www.apple.com/ pr/library/20 I I/0 I/22Apples-App-Store-Downloads-TopI0-Billion.html Date accessed: 10 Jan. 2012.

PALM, J.-M., Colombet, I., Sicotte, C. and Degoulet, P. (2006). Determinants of user satisfaction with a clinical information system. In: AMIA 2006 Symposium Proceedings, 2006 Washington DC. 614-618.

PUTZER, G. J. and Park, Y. (20I0). The effects of innovation factors on smartphone adoption among nurses in community hospitals. Perspectives in Health Information Management. I Jan. 2010. Available at: http://www.ncbi.nlm.nih.gov/ pubmed/20697467. Date accessed: 10 Jul. 20I2)

SARASOHN-KAHN,J. (20I0). How smartphones are changing health care for consumers and providers [Online]. California HealthCare Foundation. Available at: http://www.chcf. org/. Date accessed: 8 Jan. 2012.

SILVA, M. A., Tataronis, G. R. and Maas, B. (2003). Using personal digital assistants to document pharmacist cognitive services and estimate potential reimbursement. Am. J. Health-Syst. Pharm. 60, 91।-915.

STANLEY, M. (2009). The mobile internet report: ramping faster than desktop internet, the mobile internet will be bigger than most think. Available at: http://www.morganstanley. com/institutional/techresearch/pdfs/Theme_7_Emerging_ Markets.pdf. Date accessed: 7 Oct. $201 \mathrm{I}$.
Techterms.com. (20I2). Smartphone [Online]. Available: http://www.techterms.com/definition/smartphone. Date accessed: 10 Jan. 2012.

WU, J.-H., Chen, Y.-C. and Greenese, R.A. (2009). Healthcare technology management competency and its impacts on IT-healthcare partnerships development. The International Journal of Medical Informatics, 78, 7I-82.

WU, J. H. and S.C.Chang (2005). What drives mobile commerce? An empirical evaluation of the revised technology acceptance model. Information and Management, 42, 719729.

YANGIL, P. and Chen, J.V. (2007). Acceptance and adoption of the innovative use of smartphone. Industrial Management and Data System, 107, I349-1365. 